See Article page 1990.

\section{Commentary: Access to top-notch care}

\author{
John Bozinovski, MD, MSc
}

In their examination of outcomes following open thoracoabdominal aortic aneurysm replacement, Chatterjee and colleagues ${ }^{1}$ stratified patients by socioeconomic status (SES) and their reported ethnicity. ${ }^{1}$ Patients were assigned low, medium, or high SES based on median household income for their reported ZIP Code according to the US government census website. Operative mortality and midterm survival were not different across the 3 groups. Paraplegia was greater in the medium SES group. Despite apparently having no greater prevalence of comorbidities and even less kidney disease and peripheral vascular disease than the medium SES patients, those in the low SES group presented more frequently with acute symptoms requiring urgent/emergency surgery. Perhaps low-SES patients had less access to preventative health care and had more undiagnosed illness than the others, resulting in their acute presentations. The study was not designed to assess for differences in access to primary care.

Studies of SES are not without valid criticism, among which is how to determine SES. ZIP Codes encompass a wide swath of people across the SES spectrum and vary in population. Thus, there is reliance on an assumption that an individual from a ZIP Code that may contain 100,000 people is meaningfully represented by the median income of the region. Further, there is no single factor or composite to define SES. Why give greater weight to economic determinants than social determinants? Studies have shown that marital status is associated with survival following surgery. In 1 study, unmarried men fared worse than their married counterparts but this was not so for widowed men or among

\footnotetext{
From the Division of Cardiac Surgery, The Ohio State University Wexner Medical Center, Columbus, Ohio.

Disclosures: The author reported no conflicts of interest.

The Journal policy requires editors and reviewers to disclose conflicts of interest and to decline handling or reviewing manuscripts for which they may have a conflict of interest. The editors and reviewers of this article have no conflicts of interest.

Received for publication July 17, 2020; revisions received July 17, 2020; accepted for publication July 17, 2020; available ahead of print July 19, 2020.

Address for reprints: John Bozinovski, MD, MSc, N816A Doan Hall, 410 W 10th Ave, Columbus, OH 43210 (E-mail: jovan.bozinovski@osumc.edu).

J Thorac Cardiovasc Surg 2022;163:1999

$0022-5223 / \$ 36.00$

Copyright (c) 2020 by The American Association for Thoracic Surgery

https://doi.org/10.1016/j.jtcvs.2020.07.056
}

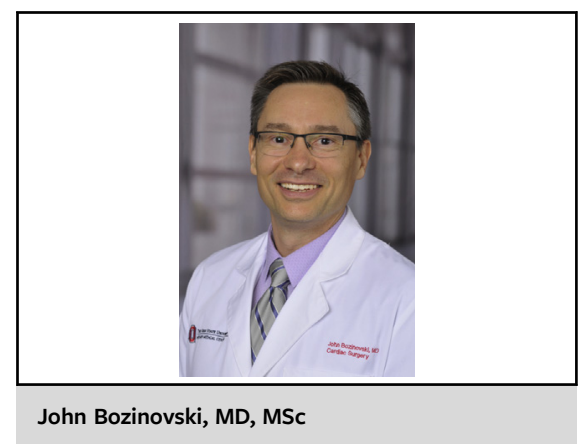

CENTRAL MESSAGE

Surgical survival based on race was not different for those fortunate enough to undergo treatment at an ultra-high-volume center, but getting to such a center may be a barrier for some.

women of any marital status. ${ }^{2}$ Although there are other options, it is difficult to convincingly argue that using median household income by ZIP Code as a surrogate marker for SES is better or worse than any other surrogate.

When looking at race, there may be barriers to access. In this study, $8.1 \%(n=67)$ of patients identified as Hispanic. Not accounting for changes in racial proportions over the era of the study and assuming aortic disease is rather evenly spread among races-which it may not be, especially if there are differences in delivery of primary health carewe can estimate the proportion of Hispanic patients that might have been found in this study if there were no barriers to access. With $11.4 \%(\mathrm{n}=95)$ of 832 patients in the study coming from the Houston metropolitan area, which is reported to be $44.8 \%$ Hispanic, ${ }^{3,4}$ and the remaining 737 patients coming from elsewhere in the United States where the population is reported to be $18.5 \%$ Hispanic, ${ }^{3,4}$ about $21 \%([95 \times 0.448]+[737 \times 0.185])$ or 179 of the patients in this study could be reasonably expected to identify as Hispanic rather than the $8.1 \%$ observed in the study. That is 2.5 -fold more Hispanic patients. Surgical survival and midterm outcomes based on race were not different for those fortunate enough to undergo treatment at an ultra-high-volume center such as the Texas Heart Institute, but getting to such a center may be a barrier for some. Eight of 9 patients reported willingness to travel to a reference aortic center and I suspect 
this is inaccurate. Certainly, 8 of 9 patients came from some distance outside the Houston area, but we do not know what proportion were willing to come from distance nor do we know how many of those willing to travel were unable to because of barriers. An easy and another, not so easy to capture aspect is how many of those presenting from outside metropolitan Houston were Black or Hispanic and what was the outcome for the non-White patients presenting elsewhere.

\section{References}

1. Chatterjee S, LeMaire SA, Amarasekara HS, Green SY, Wei Q, Zhang Q, et al. Differential presentation in acuity and outcomes based on socioeconomic status in patients who undergo thoracoabdominal aortic aneurysm repair. J Thorac Cardiovasc Surg. 2022;163:1990-8.e1.

2. Gulack BC, Hale B, White WD, Moon RE, Bennett-Guerrero E. Marriage and mortality after noncardiac surgery. J Surg Res. 2017;210:152-8.

3. United States Census Bureau. The Hispanic Population in the United States. 2019. Available at: https://www.census.gov/data/tables/2019/demo/hispanic-origin/20 19-cps.html. Accessed August 7, 2020

4. United States Census Bureau. QuickFacts: Houston city, Texas. Available at: https://www.census.gov/quickfacts/houstoncitytexas. Accessed August 7, 2020.
See Article page 1990.

\section{Commentary: Socioeconomic impact on aortic surgery: Is it about the individual, the community, or the surgeon?}

\author{
Robert B. Hawkins, MD, MSc, and \\ J. Hunter Mehaffey, MD, MSc
}

Chatterjee and colleagues ${ }^{1}$ present a well done analysis of socioeconomic status (SES) in patients with thoracoabdominal aortic aneurysm in this month's issue of The Journal of Thoracic and Cardiovascular Surgery. There are a few key take-home points that roughly translate to most cardiovascular patients. First, patients from low-SES communities present with higher acuity illness and more advanced disease. In this case, low-SES patients were more likely to present with acute symptoms, to present with dissections, and to be operated on urgently. Second, after adjustment for the differing risk profiles, low-SES itself does not affect operative outcomes (at high-performing centers like this one). Third, race and SES are inextricably linked in this country, and

\footnotetext{
From the Division of Thoracic and Cardiovascular Surgery, University of Virginia, Charlottesville, Va.

Disclosures: The authors reported no conflicts of interest.

The Journal policy requires editors and reviewers to disclose conflicts of interest and to decline handling or reviewing manuscripts for which they may have a conflict of interest. The editors and reviewers of this article have no conflicts of interest.

Received for publication July 25, 2020; revisions received July 25, 2020; accepted for publication July 27, 2020; available ahead of print Aug 3, 2020.

Address for reprints: Robert B. Hawkins, MD, MSc, Division of Thoracic and Cardiovascular Surgery, University of Virginia, PO Box 800679, Charlottesville, VA, 22908 (E-mail: rbh6x@ virginia.edu).

J Thorac Cardiovasc Surg 2022;163:2000-1

0022-5223/\$36.00

Copyright (c) 2020 by The American Association for Thoracic Surgery

https://doi.org/10.1016/j.jtcvs.2020.07.079
}

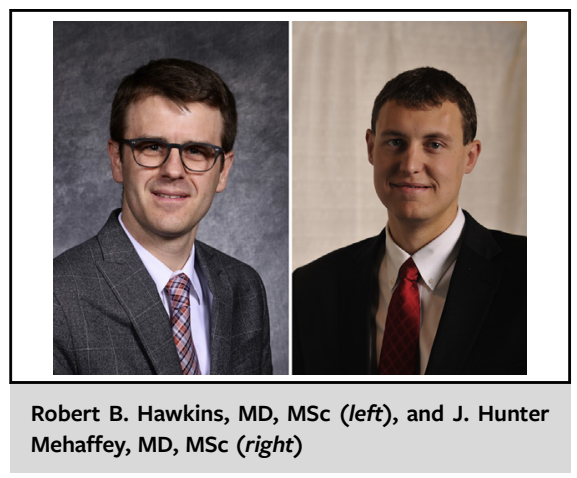

\begin{abstract}
CENTRAL MESSAGE
Socioeconomic factors contribute to disparities in aortic presentation, although thoracoabdominal aortic aneurysm repair outcomes may not differ in high-volume centers.
\end{abstract}

Chatterjee and colleagues ${ }^{1}$ found that a majority of black patients were of low SES. Notably, Chatterjee and colleagues ${ }^{1}$ report that long-term survival did not differ by SES. This differs from other studies, which have shown higher mortality with low SES, such as with coronary artery bypass grafting. In this case, the aortic pathology may be an important component, because coronary disease and heart failure are associated with greater persistent health care needs unable to be fulfilled in more distressed communities. ${ }^{2,3}$

This study highlights both the greatest strengths and worst weaknesses of the United States health care system. The private/public patchwork of insurance programs and fragmented primary care networks simply cannot provide the preventive care needed for low-SES patients. 